\title{
Framework for discussion of digital spatial data flow within cadastral systems
}

\author{
Wolfgang W. Effenberg \\ Department of Geomatics \\ The University of Melbourne \\ Australia
}

Stig Enemark

Department of Development and Planning
Aalborg University
Denmark

Ian P. Williamson

\section{Department of Geomatics \\ The University of Melbourne \\ Australia}

\section{Abstract}

Current technology and digital products such as digital cadastral maps have put pressure on institutions involved in the cadastral process to cooperate to maximise efficiencies. To discuss ways that the entire cadastral process and its users can take advantage of the opportunities offered by the current and possible future technology it is necessary to study the entire cadastral process as a single system. The authors contend that the maintenance of the digital cadastral map in any cadastral system must be viewed as a process that involves all entities in the cadastral process. This paper attempts to provide a framework, which encompasses all the spatial processes of the cadastral system, to discuss and define spatial data maintenance with a focus on the digital cadastral map. The paper proposes the concept of data flows from information systems analysis techniques to establish this discussion framework. The terminology and definitions of spatial cadastral map maintenance are defined as a basis for reviewing the digital cadastral map in a number of different jurisdictions in Australia and Europe. An examination of the processes undertaken by each of the entities or institutions within the cadastral system highlights some possible future spatial data maintenance models.

\section{Introduction}

Prior to the 1980's cadastral systems operated analogue processes supported by analogue data devices such as the paper cadastral map and hardcopy survey plans and measurements. The last two decades has seen the rapid introduction of digital technology to support the specific cadastral processes within the cadastral system. All the entities involved in the cadastral system from the surveyors and councils through to land titles offices have participated in this technology uptake. In many cases this has initially resulted in a number of digital products and processes being superimposed upon existing analogue cadastral systems.

A number of studies and reports have indicated the important social and economic benefits of having a state or nation wide, up to date and accurate digital cadastral map to support the 
spatial data infrastructure (FIG, 1995; Tomlinson Associates Ltd., 1993). The basic premise of this paper is that maintenance of the digital cadastral map either in its support of, or as a consequence of cadastral systems and in the current technological environment, is different from the entities and processes involved in the analogue cadastral system.

This paper confines itself to the digital spatial cadastral data and looks at the cadastral process as a system loosely bounded by the jurisdiction of the cadastral map. The main contention of the paper is that the maintenance of the digital cadastral map must be researched in the context of the entire cadastral system. Taking into account the needs and processes of all the entities in the cadastral system is the way to realise the goal of a single, jurisdiction wide digital cadastral map which in time can become a survey accurate and multipurpose product.

\section{The cadastral process as a system}

A single homogeneous state or nation wide cadastral product is the goal for any custodian of the digital cadastral map. The social and economic benefits of a single jurisdiction wide digital cadastral map are undermined when multiple cadastral maps are being created and maintained. New technologies represent opportunities not previously available, not only to the custodians of the cadastral map, but also to all the participants in the cadastral process and the customers of the digital cadastral maps. Some jurisdictions have attempted to cost the process of keeping the digital cadastral map up to date. The cost per parcel even for graphically accurate cadastral maps is expensive (Jacoby 1996), while improving the accuracy of this digital product is estimated to be far more costly. Clearly there is a need to look anew at the cadastral map maintenance process to address these issues.

The cadastral process of any country can be viewed as an information system and in fact much of the literature refers to a jurisdiction's cadastral system. This system includes two key components or subsystems, a spatial component, the geometric description of the land parcels, linked to the textual component, records or registers, describing the nature of interests and ownership of the land parcel (FIG, 1995). The intent in this paper is to review the spatial component of the cadastral system, the creation and maintenance of the digital cadastral map, and view it as an information system with its constituent parts, namely data, processes, people or institutions, software and hardware. The spatial subsystem is considered as a subset of the cadastral system while still fully accounting for the constituent institutions that make up the cadastral systems of the western cadastral systems examined. The application of information systems analysis techniques requires an examination of the current systems from the initial creation of the digital cadastral data by the surveyor, the other institutions involved in the cadastral system, to the intermediate or eventual customers of this spatial cadastral data This can then be represented as a spatial data flow of that system (Effenberg and Williamson 1996).

\section{The cadastral map and its maintenance}

Observation of the differences in the cadastral maps of between Europe and Australia or even the cadastral maps of the Australian states (PSMA 1996) clearly shows that there is no agreed content for the cadastral map let alone some consensus on data models. In Williamson and Enemark (1996) the cadastral map is shown as a product to service the often unique processes of a jurisdiction's respective cadastral system, a system based on the cultural, social and economic history of that jurisdiction. Nevertheless it is worthwhile to attempt to define a base content for the cadastral map to support a cadastral system and to clearly define and distinguish between upgrade and update in the cadastral map maintenance process.

\subsection{Content of the digital cadastral map}

The content of the digital cadastral map can ultimately only be determined by a careful consideration of the intended use of the digital cadastral map. Nevertheless to discuss the maintenance of the of the map it is necessary to define what data the cadastral map contains. The following is an attempt to broadly define a base cadastral map content for the purpose of 
supporting the cadastral process and the additional content (italic) required to make it a multi purpose cadastral map

Spatial data:

- parcel boundaries - often with a reference to the survey coordinate that created the parcel boundary;

- easements or right of ways;

- cadastral administration boundaries - administration of a decentralised cadastral systems;

- property boundaries - in many jurisdictions the parcel and the property are not identical;

- occupation boundaries - all land occupation boundaries such as roads, railway lines parks etc;

- general administration boundaries - these are jurisdiction dependent and include administration boundaries such as, electoral, government, planning, postal etc;

- land use boundaries - where land use categories are strictly enforced boundaries for buildings, garden, agriculture land, forest etc.

Aspatial data:

- parcel identifier - unique parcel identifier to link to aspatial databases;

- survey identifier - a reference to the original survey information or plan that created the parcel;

- street names ;

- street address -usually associated with the property rather than the parcel;

- accuracy indication - indicator of the accuracy for each point in the digital map.

\subsection{Spatial cadastral update}

Spatial update of the digital cadastral map refers to those processes that ensure that all new and existing legal subdivisions are recorded, ie. the cadastral map is up to date. Specifically this should include:

- recording all new legal subdivisions;

- ensuring map completeness including recognised backlog or holes in the map still incomplete from the capture phase. or where there is little or no subdivisional activity;

- inclusion of a proposed or planning data or layer to secure spatial cadastral updates at the planning stage, well before the titling process is completed.

\subsection{Spatial cadastral upgrade}

The obvious spatial upgrade activity associated with the digital cadastral map is an increase in the accuracy of the cadastral map by increasing the spatial accuracy of all or part of the digital spatial map content. Beyond this obvious process the following is a list of all activities which should also be included in the discussion of upgrades to the digital cadastral map:

- increase in spatial accuracy of all or any part of the cadastre;

- the inclusion of survey control and measurements;

- alignment of the cadastre with topographic features;

- changes in spatial data models to introduce (or delete) entities namely

- property boundaries

- building footprints or other land use identifiers

- street addresses

- specific aspatial attributes;

- generation of topological structures for the spatial data;

- inclusion of a historical layer to allow verification of new parcel creation; 
unique feature identification for all spatial entities.

Many of the latter cadastral upgrades mentioned can often be achieved in the process of changing the software and/or the hardware platform of the digital cadastral map. The inherent translation or migration processes of these changes often provide a cost effective means of upgrading aspects of the digital cadastre

\section{4 Spatial cadastral maintenance}

The term can be an encompassing word for both update and upgrade, it is also used to describe the instance where the update and the upgrade may occur simultaneously. For instance, the update process is often managed in such a way as to ensure that with each new subdivision that is entered, the spatial accuracy of the digital map is increased or more survey control is included. This dual process is also termed controlled update and introduces many of its own problems in terms of maintaining the integrity of the digital cadastral map, the discussion of these update and upgrade strategies is the focus of a future paper.

\section{Spatial data flow for cadastral map maintenance}

The following examples of cadastral systems attempt to document the flow of the spatial cadastral data that is created by the surveyor when changing or creating parcel boundaries in the subdivision process, and eventually perhaps incorporated into a digital map product. These spatial data flow examples come from vastly different, sophisticated, western cadastral systems and have been selected to give the broadest view of some existing cadastral maps and their role in their respective cadastral system.

The data flow diagrams are simplified to show the institutional structures that are involved, and the approximate order in which they are referred to in the cadastral process, as the spatial data flows from the surveyor to the eventual customers of the cadastral map. A deficiency of the data flow diagrams is that they do not show the iterative nature of some aspects of the cadastral process such as various approvals and referrals. Also the diagrams should not be interpreted as a linear flow for in many jurisdictions the surveyor may be required to submit data to all the bodies in the cadastral system at required times rather than the data being forwarded on by each entity to the next.

The jurisdictions have been chosen to represent the role of the spatial cadastral data in a number of highly developed western cadastral system. This divergence is represented by a cadastral system for which there is no official cadastral map, to a cadastral system where the cadastral map represents the legal parcel boundary.

Specifically the jurisdictions chosen are:

1. England - no cadastral map but large scale topographic maps are used to map the general parcel boundary if required;

2. Australia (Victoria and New South Wales) - graphical cadastre that maps the entire cadastral fabric to prescribed accuracies. A detailed review is restricted to the Victorian digital cadastral map;

3. Denmark - controlled graphical cadastre increasingly utilising survey accurate measurements tied to national control;

4. Australia (ACT) - survey accurate cadastre not part of the legal land titling or land register documentation;

5. Austria - legal survey accurate cadastre where the digital cadastral map is the legal representation of the parcel boundary.

\subsection{England}

The digital map Large scale Ordnance Survey topographic maps (urban 1:1250, rural 1:2500 
and moorlands $1: 10000$ ) giving a relatively accurate and detailed representation of the real world physical features which are sometimes adopted as boundaries.

Role of the map in boundary identification The map is only one of many resources used to establish existing property boundaries. The general boundaries system in the UK means that existing physical boundary features in nature take precedent, "pegs are paramount to plans" (Dale 1995). The topographic map would be utilised where reference is made to physical features in the associated property deeds (with or without plans) and the graphically defined Land Registry Plan (derived from deeds if property is registered).

Spatial data produced by the survey The surveyor is not legally required to be involved in the subdivision process. The plans if produced in the subdivision process are associated with the Deeds and are used to define the general property boundary. The are no legal requirements on the content or accuracy of these plans and they are often based on Ordnance Survey topographic map data.

Spatial data flow The spatial subdivision plans which might be produced are approved in the planning process and normally kept with the property deed. New boundaries are either associated with existing physical features or are suitably marked in nature with the expectation of new physical features (house wall, fence, etc) being erected.

Figure 1.

Flow of spatial property boundary data in England

Flow Diagram

At some future date normally dependant on physical activity and normal update cycles, the Ordnance Survey would survey these new and any other changed physical features and update the topographic map base.

Customers of the digital map The customer of the large scale topographic maps are all the entities in the spatial data flow, including the Land Registry who produce title plans by outlining the property in red on the Ordnance Survey topographical map to a graphical accuracy based on the deed information. Land surveyors in England are not licensed or registered and survey measurements or plans which may have been produced in the subdivision process are utilised to assist in the generation of the graphically accurate Land Registry Plan without dimensions

\subsection{Australia - Victoria}

The digital map. The digital cadastral map often termed the Digital Cadastral Data Base (DCDB) was digitised from paper maps which in turn had been compiled from individual cadastral survey plans. In rural areas the source maps were generally at a scale of 1:25000 and $1: 2500$ in towns, for the metropolitan areas scales ranged from 1:5000 to 1:200 (Effenberg and Williamson, 1997). The digital cadastral boundaries are therefore represented at a graphical accuracy, with the accuracy of the scaled boundary coordinates being about $1 \mathrm{~mm}$ at map scale (eg. $25 \mathrm{~m}$ at a map scale of 1:25000). The rural and metropolitan digital maps were developed separately and were independently managed until 1996.

Role of the map in boundary identification Victoria's digital cadastral map is a graphical representation of the cadastral fabric, it plays no legal or survey role in the identification of 
parcel boundaries. The original survey plans deposited at the titles office are used to verify boundaries

Spatial data produced by the survey The subdivision process must be carried out by a licensed cadastral surveyor to the prescribed survey accuracy and practice. The plan of subdivision contains boundary dimensions which may or may not be tied into control or local reference markers. The survey plan also includes spatial data for easement and streets.

Spatial data flow The plans of subdivision generated by the surveyor must be approved by the council before the surveyor is able to deposit the plans for the titling process. The council in turn has a number of referral bodies upon which its final approval is dependent. The custodian of the digital cadastral map updates the approved digital cadastral map after the plans have been registered at the titles office. Some plans of subdivision are forwarded to the custodian of the digital map at council planning stage and incorporated into the digital map as proposed to become part of the approved digital cadastral map after title registration.

Figure 2.

Data Flow for spatial data in Victoria, Australia

\section{Flow Diagram}

Customers of the digital map Councils and utilities utilise the digital cadastral map as a reference map for their assets with many choosing to maintain their own digital cadastral maps from the information submitted at the planning stage. The Titles Office is a potential customer of the digital map for parcel indexing purposes. The inclusion of street addresses and road centre lines in the digital cadastral map allows a derived product to be utilised by emergency dispatch services. Increasingly there is a demand for a national digital cadastral map which requires an expensive process of combining current disparate state digital maps.

\subsection{Denmark}

The digital map The country wide digital cadastral map, based on the national grid network, is to be completed by 1997 . The digital map is essentially a controlled digitisation of the old analogue island maps of individual village areas surveyed by plane table at the scale of 1:4000, not based on any local or national control network. The national control points and connected cadastral surveys formed the skeleton digital map (urban $40 \%$, rural $20 \%$ ). The remaining digitised cadastre was inserted into the skeleton map by transformation often using the digital topographic map as control. The accuracy of the boundary coordinates range from a few centimetres in some urban areas to several metres in some rural areas.

Role of the map in boundary identification A licensed surveyor compares the legal survey information (cadastral map and legal survey measurement sheets) to the monuments, occupations, fences, etc, in nature, with the surveyor having the responsibility of resolving any discrepancies. Where there are no useful legal survey measurements, the cadastral map which was in use at the time of establishing the boundary must be used as the main information for boundary determination, taking into account that the graphical boundaries in the digital cadastral map may have been distorted during the digital map production process.

Spatial data produced by the survey Licensed surveyors produce accurate positioning of new parcel boundaries, normally connected to the national control grid and presented as legal survey measurements sheets. (road info, building footprint etc??) 
Spatial data flow When land is to be subdivided or boundaries changed landowners must employ a private licensed surveyor for the necessary legal surveys and the preparation of documents needed for submission of an application to the National Survey and Cadastre (NSC) for updating the cadastral register and the cadastral maps. The application must contain a copy of the cadastral map showing the alteration of the boundaries, measurement sheets showing the new boundaries, documentation proving legal rights and documentation showing the approval of the future land use according to planning and land use regulations.

Figure 3

Spatial Cadastral Data Flow in Denmark

The approval by the NSC, showing the updated cadastre and the updated cadastral map, is returned to the private licensed surveyor and is forwarded to the municipality to update the property tax register, and to the local Land Registry Office to update the Land Book. Survey information or cadastral maps must be obtained from a local private surveyor or the NSC.

Customers of the digital map Denmark's cadastre is accepted as providing the basic infrastructure for managing economic interests in land as well as supporting environmental and development interests. (Enemark, 1992). The customers therefore are found within the private sector (real estate agents, lawyers, engineers, architects, surveyors, etc) as well as the public sector (local, regional and national authorities).

\subsection{Australia -Australian Capital Territory (ACT) (PSMA 1996)}

The digital map The cadastral map is referred to as the Cadastral base of ACTMAP and is a fully coordinated urban cadastre. The ACTMAP Land Information System additionally holds street addresses, building footprints, building names, all administrative boundaries, road centre lines, kerbs, survey control, 2 metre contours, water features and utility information. There are about 105,000 urban parcels held at survey accuracy, a small number of rural parcels held at varying lower orders of accuracy and the remainder being national park.

Role of the digital map in boundary identification The accurately positioned coordinated reference marks (CRM) positioned every 150 metres along every street in Canberra allow the surveyor to fit the real world subdivision to the cadastral map to within 3 centimetres relative to the nearest CRM.

Spatial data produced by cadastral survey Depending on the size of the subdivision the cadastral survey by a licensed surveyor will produce (by the time subdivision building is complete) survey control, survey accurate subdivision plans and computation sheets and kerb based CRMs,

Spatial data flow The nature of the ACT land systems approved subdivision data (AP) is forwarded to the cadastral map well before final and survey accurate plans are prepared for the Deposited Plan (DP) to be registered at the Titles Office (see figure 4).

Figure 4.

Spatial Data Flow in the ACT of Australia 
This means that the Cadastral map has two classifications of data, namely planning data and final accurate data. The names refer more to the data accuracy provided by the surveyors, with many surveyors supplying accurate data from the outset of subdivision planning. All parcel data within the cadastral map must be accurate before the Deposited Plan for that parcel can be registered at the Titles Office.

Customers of the map The nature of the ACT government means that the office maintaining the cadastral map deals at a local council level with the private surveyors and also fulfils the state function of cadastral map maintenance. ACTMAP is the core data set used by all the ACT government and utility companies that operate a LIS/GIS system, with direct access to the cadastral map details both at the planning and registered stages.

\subsection{Austria}

The digital map The digital cadastral map was derived from the cadastral maps first produced in the mid to late nineteenth century for taxation purposes and is a survey accurate map of the legal borders of parcels. The digital map also contains survey accurate spatial data to define land use boundaries, with the main categories being building (building footprint) garden, farm, forest etc, and to facilitate land use area calculations. The digital map is fully integrated with the aspatial land register and the database of coordinates for all border and survey control points The legal digital map is approximately 60 to 70 percent complete and is created and maintained by sixty-eight local survey offices with the centrally stored Austria wide legal cadastre held by the Federal Office of Surveying and Metrology ( $\mathrm{H}$ flinger, 1993).

Role of the map in boundary identification The subdivision documents and the associated database of the control and border points is the legal parcel boundary. The digital map is an survey accurate representation of all recent boundary documents. It is the role of the surveyor to ensure that subdivision surveys accord with the legal cadastral map and its supporting survey documents. If the boundary in nature differs to the boundary designated in the digital map, the surveyor is required to involve parties to that boundary in order to survey the new agreed boundary and submit measurements and appropriate legal agreement documents to authorise the change to the current legal digital cadastral map.

Spatial data produced by the survey Licensed surveyors conduct cadastral surveys to accurately and legally define the parcel boundary and all designated land use boundaries and classifications. All the cadastral survey data is tied to an extensive national control network.

Figure 5.

Data flow for spatial data in Austria

Spatial data flow The surveyor bases his subdivision survey plan on measurements extracted from the central database of border and control points. The plans of subdivision are deposited at the local survey office where they are held for a maximum of two years awaiting legal 
approval. The subdivision plan is entered into the central legal digital cadastral map at each of the local survey offices. The incremental creation of the digital map is also contracted out to the surveyors by the local survey office

Customers of the digital map The digital cadastral map along with the land register are open to public access at any of the local survey offices at minimal cost. A videotex system gives direct access to all interested persons including surveyors, the legal profession, councils, banks.

\section{Entity processes in cadastral spatial data flow models}

The five data flow models show a consistency in the entities that are involved in the cadastral systems. While the entities of the reviewed cadastral systems are similar, the processes that they individually enact in the creation and maintenance of the cadastral map vary significantly. In order to generate a high level system view of the spatial cadastral processes each of the entities or institutions are more closely reviewed to summarise the possible processes that each undertakes. This summary of the entities across the different cadastral systems provides the basis for identifying the high level processes involved in the production and maintenance of the digital cadastral map.

\subsection{The cadastral or land surveyor}

The spatial cadastral data originates with the surveyor and they are increasingly generating the cadastral data in digital format using current survey technology. The surveyors' role varies from no involvement to the almost direct inclusion of the survey data into the cadastral map. The surveyor is increasingly required to include survey control and can be also required to place control where required. The surveyor is contracted to create portions of the digital cadastral map in Austria where an incremental creation process is under way. In Austria and Denmark the surveyor holds the primary legal responsibility and facilitates the mechanism for the changing of legal property boundaries. The surveyors' processes are subject to scrutiny, either by checking mechanisms by subsequent cadastral system entities, by the surveyor being in the employ of one the other cadastral system entities (council or custodian) or by virtue of the legal responsibility for the spatial data resting with the surveyor.

\subsection{The local councils and utilities}

In each case the local council, municipality or its equivalent is charged with enforcing local planning and land use regulations, the spatial data is restricted from further entry into the cadastral system until the councils approve the plans to ensure that they adhere to all applicable planning regulations and until they receive approval from utilities and other referral bodies.

Many councils and utilities each input the spatial cadastral data for their own planning purposes particularly if the cadastral map is a post title product divorced from the planning process. Whether the planning cadastral data they enter goes on to update the their own version of the cadastral map, or is discarded, is dependent on the perceived accuracy of the state cadastral map and ease of incorporating spatial update at a later date.

Utilities and some larger councils were often fore runners in the digital cadastral map product and indeed their data formed basis of much of the Australian cadastral maps (Effenberg Williamson 1997). These institutions, often charged with accurately mapping their underground assets, have probably have the greatest interest in survey accurate, multi purpose cadastral maps and often maintain their own cadastral maps based on their business needs and the perceived deficiencies in the state digital product. On the other hand they can also partnership the state digital cadastral product both in financial and maintenance aspect.

\subsection{Titles body}


The processes of the titles body may vary from a no involvement in the spatial data and merely granting title on the basis of spatial data previously verified by another entity; to the titles body undertaking a rigorous survey check of the surveyor's subdivision measurements and planning approval status. In the case where the cadastral map defines the legal extent and boundaries of the parcel the currency of the digital map may be measured in months and years. In many cadastral systems the titles body and the custodian of the cadastral map are the same institution operating in different areas with close cooperation. In all cases the titles body or its decentralised court equivalent is usually the custodian of land register or land book holding the ownership and legal rights relating to the cadastre and defines the completion of the legal process of the cadastral system

\subsection{Cadastral map custodian}

The necessity for a base map to support the jurisdiction wide spatial data infrastructure has led either to the tasking of existing institutions or the formation of a new body to undertake the creation and custodianship of a state or national digital cadastral map. Once created and marketed the national digital cadastral map becomes increasingly required to fulfil a multi purpose role. Stewardship of jurisdiction wide cadastral map means applying standards to the spatial data in the update and upgrade procedures, maintaining the content and accuracy of the jurisdiction wide cadastral map to ensure that it meets its intended legal or spatial infrastructure requirements. The creation and maintenance of the cadastral map may be performed either in a centralised or decentralised manner, by either the custodian or its offices or contracted out to a third party. The maintenance process may be pre or post titles office (pre or post legal status) but is rarely at the planning stage.

\subsection{The spatial cadastral system}

The creator of the spatial cadastral data is normally the surveyor whose plans must be verified by or comply with municipality or local council planning regulations and land use laws with further reference to utility planning. The titles body is usually the custodian of land register or land book recording the ownership and legal rights relating to the cadastre. The linkage between the titles body and the custodian of the cadastral map dependent on the extent to which the digital map is part of the titling process.

Irrespective of the role of the cadastral map and its intended function within the complete cadastral system, for the spatial cadastral system, there is a creator of the update information which is normally the surveyor and at the end of the cadastral process there is a digital cadastral map. The spatial data produced by a boundary change or the subdivision process is subject to planning and land use regulations, a process normally conducted by the council or municipality in consultation with the relevant utilities. The legal verification and graphical manipulation spatial data to conform to the cadastral map standards appears normally to be the jurisdiction of the custodian of the cadastral map in conjunction with the titles office.

Figure 6 depicts this interpretation of the high level processes and the input and output entities of the spatial cadastral system.

Figure 6.

The high level spatial cadastral system

\section{Technology and the high level cadastral processes}


Current and future technology will influence the implementation of these three high level processes both in how the processes are implemented and what entities are involved in the implementation. The digital environment and the Internet technology should be utilised in these processes to ideally exclude the time delays and duplication that is often inherent in current cadastral systems. The following clarification of these three spatial cadastral processes and the associated technological possibilities provides the framework to explore future digital cadastral maintenance models.

\subsection{Creation of spatial cadastral data}

The survey is the basis for the spatial data that will construct the spatial cadastral data to update the digital cadastral map. It should only be necessary to enter the spatial cadastral data once (digital spatial data creation) and the technology of the Internet allows this spatial data to be instantly visible to all agencies involved in the cadastral process such as councils, land titles offices and the custodian of the jurisdiction wide cadastral map. The entry of new parcel information and manipulation of the cadastral map can be done at remote locations with structured access to the current or legal digital cadastral map. The new spatial data can be multiply held to reflect as measured or as fitted in relation to the cadastral map and structured to denote the status of the spatial data, ie planned, proposed, legal, etc.

Modern surveying techniques and equipment means that regional survey control can be accurately and cheaply set out, the cadastral survey is easily tied to control and multiple survey information can be effectively collected when on site.

\subsection{Application of land use plans and regulations}

The process of confirming that the proposed subdivision meets all the necessary local and jurisdiction wide regulations is often spread across a number of entities of the cadastral system. Internet technology allows for relevant land use plans and regulations to be freely available to all entities and individuals whether or not they are part of the cadastral system. and application of these plans and regulations need not be a centralised process. It is possible to electronically signature digital spatial plans to identify their origin. It is also feasible to digitally signature and confirm compliance with regulations and to authorise the change of status of spatial cadastral data from for example from planned to legal. To ensure that subdivision activity does not occur in specified or planned areas, portions of the digital cadastral map can be locked to prevent subdivision activity, either permanently or on periodic basis.

\subsection{Application of standards to spatial data}

Application of standards to spatial data occurs in three areas, the application of quality controls to the survey data, a check of the legality of the subdivision plan and the application of standard procedures and quality control to ensure the correct maintenance of the cadastral map. The first standard is commonly achieved by the use of survey regulations and the licensing of surveyors. To ensure that the subdivision is legally within its stated boundaries a preapproval process is possible where isolated areas of the cadastral map base can be checked out, new subdivision measurements can be entered and the acceptability this spatial data can be automated (Elfick, 1995). Lastly licensed entities or individuals accessing or manipulating the spatial cadastral map data for maintenance purposes can always be monitored, restricted and audited.

\section{Models for the maintenance of the cadastral map}

The legitimate requirements of maintaining a central database of legal survey measurements or a homogenous jurisdiction wide digital cadastral map do not necessarily dictate a centralised maintenance model. Central to feasibility of the following models for the maintenance of the cadastral map, is that with digital formats and Internet technology, where and on what hardware and software platform the digital cadastral map resides is transparent to the entity or 
individual viewing, maintaining and down loading or up loading the digital cadastral data. In addition the concepts of distributed databases negates the necessity of the entire database or digital cadastral map residing at a single (central) location.

\subsection{Centralised model}

Traditionally the cadastral map is created and maintained by the custodian of the jurisdiction wide cadastral map in a centralised manner. The majority of cadastral systems reviewed are based on centralised models which rely on the information being forwarded or requested by the custodian of the cadastral map and the approved spatial data being returned to the other entities or customers of the cadastral system. That is the process application of standards to the spatial data is carried out by either or both the titles body or the custodian of the cadastral map. The basis for a centralised model is generally in the context of central control, central approval. and the perceived requirements for the individual business need and for the efficiency and quality of the single jurisdiction wide cadastral map.

\subsection{Decentralised models}

Technology affords the opportunity to consider totally decentralised or remote maintenance of the digital cadastral map where the spatial cadastral processes are undertaken by entities other than the central custodian. These possible decentralised models are outlined here as a consequence of the system analysis to provide a framework for future discussion of their jurisdiction specific application and validity.

Regional model The Austrian cadastral system is an example of this model where the federal survey office has 68 decentralised offices that handle the creation and maintenance of the digital cadastral map for that geographical area. This decentralised model is a consequence of the historical analogue cadastral system and as a result of current reorganisation from the 1st January 1998 the number of offices has been reduced to forty-one While the other processes of the cadastral system remain with their entities the process of application of standards to spatial data therefore becomes a decentralised process centrally controlled.

Utility model Utilities, normally referral entities and customers of the spatial cadastral system, generally maintain a cadastral map component for their asset inventory while not being involved in the cadastral titling process. In the graphical cadastres of the Australia states the majority of the initial digital cadastral data was sourced from metropolitan water utilities, many of these utilities maintain their own digital cadastral maps utilising planning data. Where a utility divides the jurisdiction into geographic regions, this utility could additionally undertake the application of standards to spatial data process for that geographical portion of the cadastral map. In effect a number of utilities undertake the maintenance of the digital cadastral map on behalf of the cadastral map custodian. The role of the custodian is then to set standards and quality control to ensure the integrity of the jurisdiction wide cadastral map.

Council model In this model the council incorporates the of process of applying standards to the spatial data into its current activities of applying land use plans and regulations. The essential differences between this model and the utility model are that the councils are involved in the cadastral titling process by way of legal approval of subdivisions in complying with planning and land use regulations and that the number of council entities within a jurisdiction is a greater number. If the surveyor is in the employ of or contracted to the council then the all the spatial cadastral process could be enacted by a single entity.

Surveyor model The ultimate decentralised model has the process of gathering, maintaining and onward distribution of the cadastral map maintenance data resting with the creator of the spatial cadastral data. Here licensed survey entities (surveyors or smaller pseudo cadastral offices) undertake all the processes of the spatial cadastral maintenance subject to prescribed standards in conjunction with a process of quality control and audit. 


\subsection{Costs and benefits}

The costs and benefits of the above models are difficult to quantify without taking into account the specific jurisdictions economic and cultural factors. The issue is that in a totally digital environment there will be no need for central approval, the spatial cadastral dataflow can be based on standards and a processes of quality control that should, ideally exclude all kinds of time delays and duplication.

For a single jurisdiction wide multi purpose cadastral map there is a need to move towards a survey accurate coordinated cadastre. The cost of central creation, the time required and the lack of availability of survey accurate data are the reason for jurisdictions digitising graphically accurate cadastres. The modern economic principles relating to cost recovery and user pays are also prohibitive cost factor. The models that encourage cadastral upgrade towards a coordinated cadastre will be more cost effective in the long term.

The decentralised models offer the advantage of effectively capturing the cadastral maintenance data at the planning stage and the possibility being able to link cadastral upgrade with any kind of local development. Continual upgrade is much higher when the decentralised or remote maintainer (and user) perceives immediate knowledge and benefits of the changes.

However, the decentralised maintenance models require access to the cadastral map, access to current planning and land use regulations. Specifically for survey purposes the digital cadastral map, the survey measurements held for cadastral purposes and survey control information must be freely available to the surveyor and a mechanism for preliminary legal approval of subdivisions and or other cadastral upgrades to the existing cadastral map within specified property boundaries.

\section{Conclusion}

The update and upgrade of the digital cadastral map is a focus of concern for all the diverse western cadastral systems reviewed in this paper. The review demonstrates that the systems are a product of the cultural and social influences of their jurisdiction. In this context the paper presented a content for the cadastral map or map layer and clarified the definitions of spatial cadastral update, upgrade and maintenance as a basis for discussing cadastral maintenance models.

The application of a systems analysis approach and the documentation of spatial cadastral systems using a high level dataflow diagrams provides a framework to compare and contrast these systems and to discuss ways in which the maintenance of the digital cadastral map can adopt the benefits of current technology to benefit all its participants and users.

Technology is creating the possibility of decentralised or remote maintenance of the spatial cadastral data. These maintenance models presented again provide a framework for discussion of spatial cadastral maintenance and their jurisdiction specific application. This basis for continuous improvement in the digital cadastre and decentralised maintenance is an accurate cadastral map tied to the national control network. The costs and benefits of decentralising the responsibility for spatial cadastral maintenance will include other considerations such as copyright, institutional politics, etc which are not within the scope of this paper.

The digital cadastral map must realise its full potential as a multipurpose map in support of the spatial data infrastructure. Cadastral information is a basic component of any GIS system dealing with land information, and the organisation of the processes of providing and maintaining the cadastral data should reflect serving the users needs instead of only serving the needs of the jurisdiction's cadastral system.

\section{ACKNOWLEDGMENTS}


The authors wish to gratefully acknowledge the support of Geospatial Policy and Coordination Victoria (GPAC) and Geographic Data Victoria (GDV) of the Victorian Government, the Land Information Centre (LIC) of the New South Wales Government, and the Australian Research Council (ARC) The authors also wish to gratefully acknowledge the suggestions and comments for the country specific summaries from Dipl. Ing. Gerda Schennach (Austria) and Alan J. Roberts FRICS, Finst CES. (England). The views expressed in this paper are those of the authors and do not necessarily reflect the views of the individuals or agencies mentioned.

\section{REFERENCES}

Dale P. (1995) The Cadastral System and Land Registers in England - There are also other ways to do it. Maankaeytto 1/95, Helsingfors

Effenberg, W. W. and I. P. Williamson (1996) Data flows, standards and incremental cadastral update. Proceedings of the 8th Annual Colloquium of the Spatial Information Research Centre, Dunedin, New Zealand, 9-11 July, Spatial Information Research Centre, University of Otago

Effenberg, W. W. and I. P. Williamson (1997) Digital Cadastral Databases, the Australian Experience. Proceeding of the AGI conference at GIS 97, 7-9 October. Birmingham, England.

Elfick, M.H. (1995) A Cadastral Geometry Management System. The Australian Surveyor, March 1995 pp. 35-40.

FIG (1995) International Federation of Surveyors. Statement on the Cadastre. FIG Bureau, Canberra, Australia.

H flinger, E. (1993) From Cadastre to Land Information System. Proceedings of the 40th Congress of Italina Consiglio nazionale Geometri, Florence, June 1993

Jacoby, S. (1996) Incremental Updates and Associated Issues.

Proceedings of WALIS forum '96 Perth Australia 23-24 April 1996.

http://www.walis.wa.gov.au/forum/forum96

PSMA, (1996) Report on the PSMA/ICSM Workshop on Digital Cadastral Data Bases, Melbourne 5-7 August, 1996. Public Sector Mapping Agencies, Canberra, 85p.

Tomlinson Associates Ltd. (1993) GIS Strategy Report, State Government of Victoria Strategic Framework for GIS Development. Office of Geographic Data Co-ordination

Williamson, I. P. and Enemark, S. (1996) Understanding cadastral maps. The Australian Surveyor, 41(1), pp. 38-52.

\section{Biographical Sketch}

\section{Wolfgang Effenberg}

BSc RMIT, DipEd VIC, GradDipCompStud Canberra, MAppSc Melb.

Wolfgang Effenberg is a lecturer in Information Technology at Latrobe University, Bendigo, Victoria, Australia. Prior to his current academic career he worked for six years as a software engineer and consultant in the digital mapping, CAD and CAD/CAM industry. He obtained his Masters at Melbourne University in 1994 with research into temporal considerations of digital road networks. He is also a part time PhD candidate in the Department of Geomatics at The University of Melbourne, Victoria, Australia. His current major research focus is the investigation and utilisation of current computing technologies and communication in managing the update 
and upgrade of spatial data.

\section{Stig Enemark}

Stig Enemark Senior Associate Professor, Reader Department of Development and Planning Aalborg University Denmark. Research interest is in the area of Spatial Planning systems and Cadastral systems.

\section{Ian Williamson}

BSurv(Hon), PhD (NSW), FISAust, FIEAust, LS, CP Eng

Ian Williamson holds the Chair of Surveying and Land Information in the Department of Geomatics at The University of Melbourne, Victoria, Australia. He holds bachelors, masters and doctorate degrees in Surveying, is a Registered Professional Land Surveyor and a Chartered Professional Engineer. Professor Williamson is both a Fellow of the Institution of Surveyors, Australia and the Institution of Engineers, Australia. Prior to his academic career, he worked for a state government in Australia, an engineering corporation based in the USA and ran his own consultancy practice. He is Chairperson (1994-98) of Commission 7 (Cadastre and Land Management) of FIG. He has consulted widely to state and federal governments in Australia and overseas, United Nations agencies and the World Bank. 


\section{University Library}

\section{- M M N E R VA A gateway to Melbourne's research publications}

Minerva Access is the Institutional Repository of The University of Melbourne

Author/s:

Effenberg, Wolfgang W.;ENEMARK, STIG;Williamson, Ian P.

Title:

Framework for discussion of digital spatial data flow within cadastral systems

Date:

1999

Citation:

Effenberg, W. W., Enemark, S., \& Williamson, I. P. (1999). Framework for discussion of digital spatial data flow within cadastral systems. The Australian Surveyor, 44(1), 35-43.

Publication Status:

Published

Persistent Link:

http://hdl.handle.net/11343/33990 